\title{
The cytology of gastric mucosa
}

\author{
W. C. D. RICHARDS AND A. I. SPRIGGS \\ From the Department of Pathology, United Oxford Hospitals
}

SYNOPSIS Smears and sections were obtained from various labelled points on the mucosal surface of 25 freshly-excised stomachs, and the appearances were compared. Normal gastric mucosa, intestinal metaplasia, chronic gastritis, and carcinoma could generally be identified from the smears. $\overrightarrow{+}$ In a few smears from the edge of peptic ulcers there were abnormal cells which might cause con $-\stackrel{-}{-}$ fusion with carcinoma. Conversely, tumour cells were seen which would be very hard to diagnose $\mathrm{N}_{\mathrm{N}}^{\mathbf{w}}$ with certainty on cytological grounds.

The cytological examination of stomach contents has been used sporadically for the diagnosis of gastric carcinoma for over 50 years (Marini, 1909) and during the past decade has been the subject of numerous papers (see Rubin, 1956; Raskin, Kirsner, and Palmer 1958) and of two monographs (Henning and Witte, 1957; Schade, 1960). In spite of all that has been written, the pathologist examining gastric washings still encounters serious difficulties, especially in the separation of malignant cells from the altered cells which are sometimes found in chronic gastritis.

Heinkel, Witte, Landgraf, and Elster (1956) made a comparison between the findings of blind gastric biopsy and cytodiagnosis (the latter performed by the technique of Henning and Witte with a gastric swab). Only the varieties of gastritis were under investigation, and these authors described and illustrated abnormal cells which can be found in nonmalignant conditions. It could not be claimed that the smears came from the areas of gastric mucosa taken for section, and in fact correlation was not very close. Although other workers in this field have no doubt made direct comparisons between smears and histological sections of the same area of gastric mucosa (Schade, 1958), they do not seem to have published their experiences. The present paper describes our findings in a direct comparison of smears and sections.

\section{MATERIALS AND METHODS}

The material consisted of 25 gastrectomy specimens. In nine cases a carcinoma was present, in eight cases the lesion was a benign gastric ulcer, and in eight cases the gastrectomy was performed for a duodenal ulcer alone.

Received for publication 19 July 1960. In one instance both a duodenal and gastric ulcer were $\frac{3}{3}$
present.

Each specimen was taken directly to the laboratory, $\overrightarrow{0}$ opened along the greater curvature, and then pinned on aos cork board before fixation. From three to 12 differentareas were selected for study.

Each area chosen was scraped with a scalpel and smears made on a glass slide with the scalpel blade. It was found that wooden or cardboard instruments were ineffective in removing surface epithelium. The smears were wetक fixed in alcohol containing 3\% acetic acid.

They were stained by Papanicolaou's method as wello $\overrightarrow{\overrightarrow{0}}$ as by periodic-acid-Schiff (P.A.S.) or Mayer's mucicarmine (the latter was the better, as there was a tendency? with P.A.S. for the cells to be obscured by brightly stained? mucus). The areas from which the smears were obtained were labelled with numbered pins and the whole speci-O men fixed in $10 \%$ formal saline. After fixation, sections were taken of the numbered areas and stained with haematoxylin and eosin and with P.A.S.

In this way a series of histological sections of gastric mucosa was obtained together with smears of theo epithelium from the same site. The material studied is classified in the Table.

\section{RESULTS}

The results were classified according to the histo-N logical appearances but without regard to the dif $-\frac{\omega}{O}$ ferences in distribution of the lesions in individual specimens.

NORMAL GASTRIC MUCOSA Normal gastric body mucosa was found in 16 sections from eight cases. Mild or focal superficial gastritis without abnor- $-\mathbb{D}$ mality of the superficial epithelium was found in 12 sections from nine cases. Thus a total of 28 sections (from 12 different cases) showed normal or almost normal gastric body mucosa. 


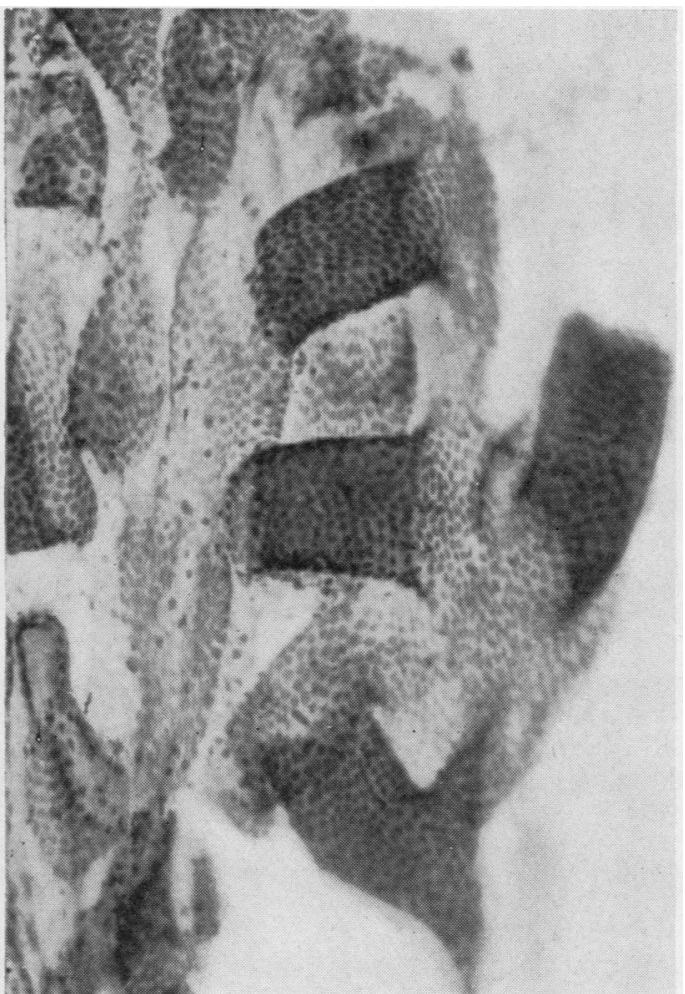

FIG. 1

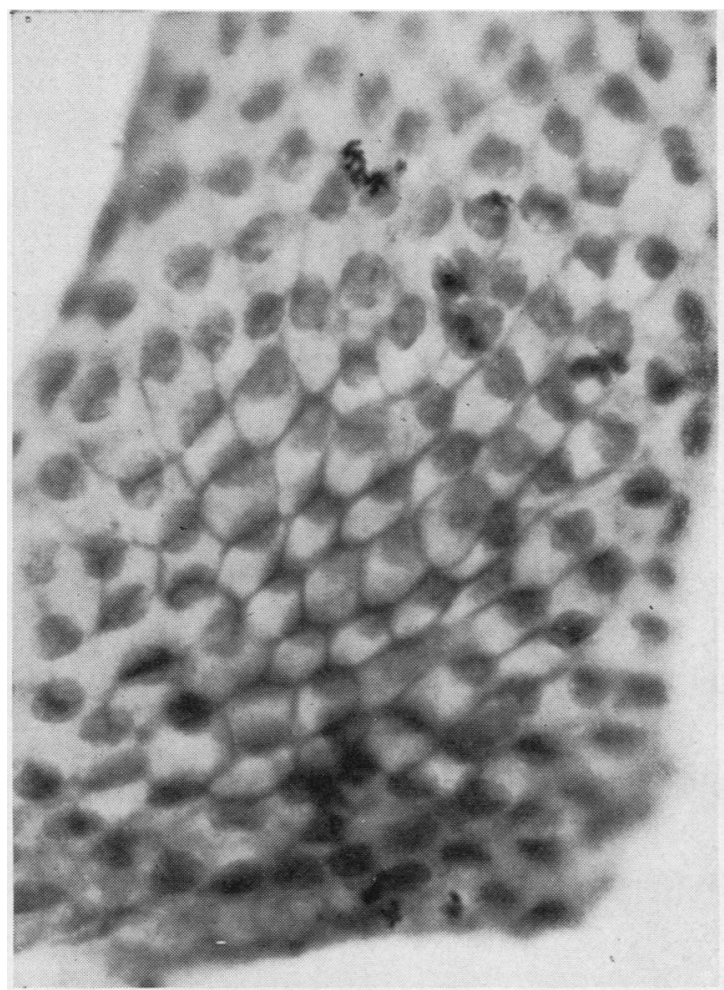

FIG. 2

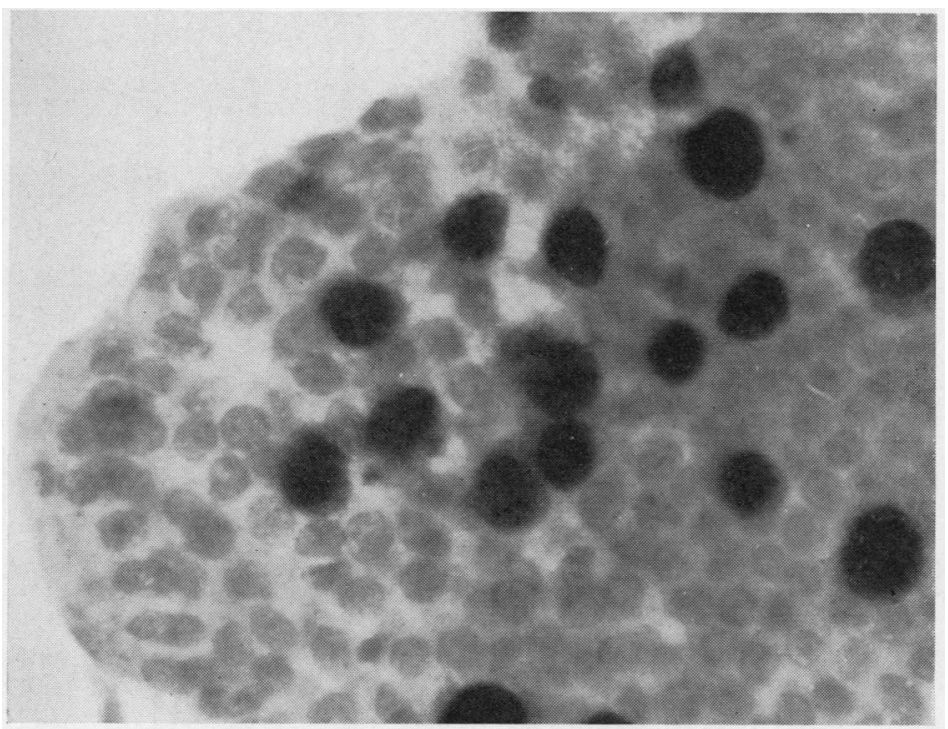

FIG. 1. Smear from normal gastric fundus. The sleeve-shaped structures are the linings of gastric pits. (Case G 101 area 6) (Papanicolaou $\times 150)$

FIG. 2. Smear from normal gastric fundus (higher magnification of the same specimen as Fig. 1). The mucous vacuoles produce a honeycomb pattern. (Case G 101 area 6) (Papanicolaou $\times 700$ )

FIG. 3. Smear from duodenal mucosa, stained with P.A.S. The mucin in goblet cells is shown as darkly stained spheres overlying the nuclei. (Case G 51 area 5) (P.A.S. $\times 700)$

FIG. 3 
No completely normal sections of pyloric mucosa were obtained but very little change in the surface epithelium was noted in many sections taken from areas distant from any gross lesion.

When scraped, the superficial layer of the fundic mucosa peeled off in sheets of adherent cells. Many thousands of cells were often present in one fragment in the smears. Funnel-shaped structures resembling the fingers of mittens represented the epithelium lining the gastric pits (Fig. 1). When seen in the plane of the mucous vacuoles, the cells had a characteristic 'honeycomb' pattern made up of refractile hexagons (Fig. 2). This effect was lost when the cells were in small groups or were isolated. The nuclei were uniformly round or oval and did not exceed $11 \mu$ in diameter. Most of them contained a single nucleolus but some had two. The cytoplasm was only feebly stained with mucicarmine but gave a positive reaction with P.A.S. Although the groups of cells seen in smears from the pylorus did not show such a distinct architecture as those in the smears of normal gastric body mucosa, no real cytological difference was detected.

DUODENAL MUCOSA Thirteen sections from 11 cases consisted of or included duodenum. There was frequently some increase in lymphocytes and plasma cells in the lamina propria but in only one section was part of an ulcer seen, and the villi showed no gross distortion.

The smears from the duodenal mucosa showed sheets of cells with a similar but less marked 'honeycomb' pattern to those present in the stomach. Some of the sheets corresponded to the tips of villi. Goblet cells were well shown in smears stained for mucin (Fig. 3) and brush borders could be seen. The epithelial cell nuclei appeared identical to those of the gastric epithelium.

GASTRITIS A total of 79 sections from 24 cases showed gastritis. The morphological changes observed were similar to those described in gastritis by other workers (Magnus, 1937, 1946; Palmer, 1954; Joske, Finckh, and Wood, 1955). The severity of the lesions varied considerably even in individual sections, but although abnormalities of the surface epithelium were not always pronounced, the lamina propria always showed increased numbers of plasma

TABLE

HISTOLOGICAL MATERIAL

Site

Stomach

Duodenum only

Edge of benign peptic ulcer of stomach

Carcinoma of stomach

Total cells and lymphocytes. Severe atrophic gastritis waS found in six sections of gastric body mucos孚 Sections of the pyloric mucosa and of the mucosa at the edge of the carcinomata and peptic ulcers almost always showed some degree of gastritis.

Active gastritis was frequently found in section taken from the vicinity of the peptic ulcers ang carcinomata. In such cases the surface epitheliax cells were abnormal and neutrophil leucocytes were present in the surface epithelium and lamina propria. The surface epithelium was composed of flattenefs or cuboidal cells which had a darkly staining cytos plasm and a much reduced mucin content. The nuclei tended to be prominent and were sometimes enlarged with prominent nucleoli.

In smears, lesser degrees of superficial gastritis were not associated with any cytological changes it the epithelium. In more severe chronic inflammation the 'honeycomb' effect produced by the mucus secreting layer was lost. Leucocytes (neutrophils an $\Phi$ lymphocytes) were present in the sheets of mucosas cells and appeared to lie intracellularly. In most instances there was no particular change in the nuclei, but sometimes there was abnormal variation in size, heavier haematoxylin staining of the chroe matin, and prominence of the nucleoli (Fig. 4).

In a few of the smears from areas of active gastritis particularly at the edge of an ulcer, there was 8 considerable degree of anisonucleosis. In the example illustrated in Figs. 4 and 5, some of the nucles measured as much as $15 \mu$ in their long axes, an $\vec{A}$ they showed considerable overcrowding. The nucleo were prominent, and in certain areas were stained red in the Papanicolaou preparations.

Smears obtained with the scalpel included what ever leucocytes were present in the lamina propria. In some cases plasma cells were numerous. Thes cells have not in our experience been present in gastric washings (although 'pseudoplasmacytes'pyknotic forms of epithelial cells sometimes cons taining hyaline droplets-may be abundant). Plasma cells were not seen in or among the epithelial cel $\overline{\text { S }}$ in sections, and it appears that they do not penetrate the mucosa.

In one case of gastric ulcer the smears contained collections of what appeared to be cells from the gastric glands. The corresponding section showeg a group of gastric gland cells apparently extrudef on to the surface (Figs. 6 and 7). Although this appearance is sometimes seen in histological sections the glandular cells do not seem to be recognizable in saline washings from the stomach. They have however, been seen in gastric swab preparations bo Henning and Witte (1957).

No case of Addisonian pernicious anaemia was included in this series. 


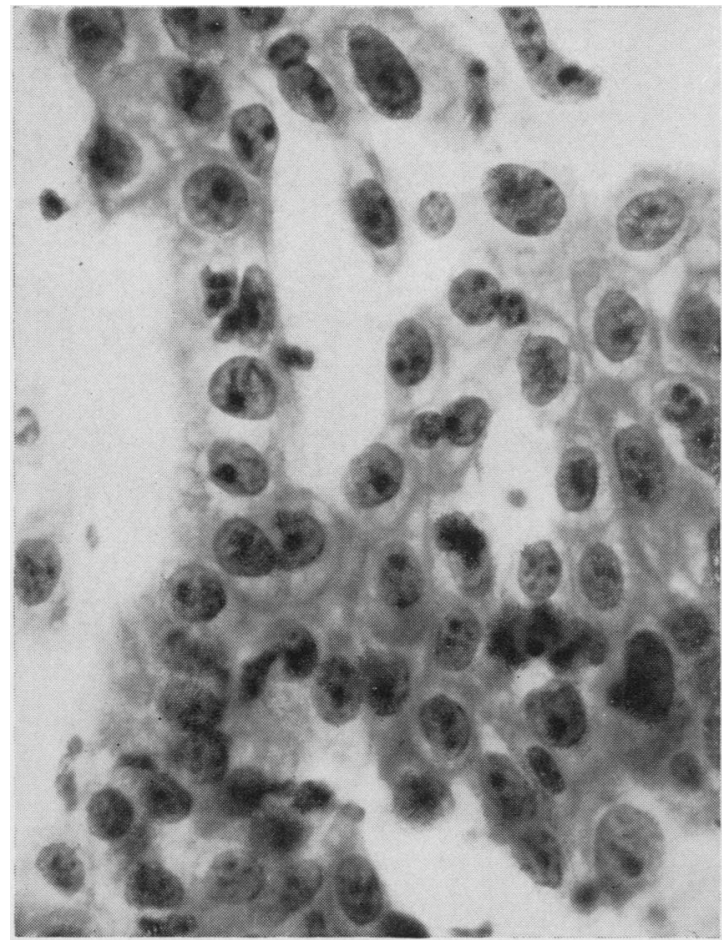

FIG. 4. Smear from the edge of a simple gastric ulcer. The mucous vacuoles are lost, and the nuclei show variations in size, hyperchromasia, and prominent nucleoli.

(Case G 97 area 6) (Papanicolaou $\times 700)$

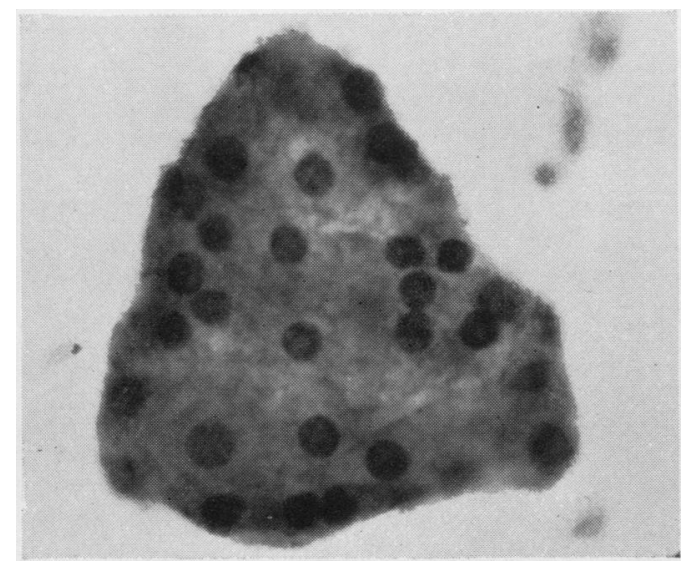

Fig. 6

FIG. 6. Smear from an area of chronic gastritis, showing a collection of cells from a gastric gland.

(Case G 18 area 10) (Papanicolaou $\times 700)$

FIG. 7. Section showing fundic gland cells on surface of gastric mucosa. Chief and parietal cells are present. Same area as Fig. 6.

(Case G 18 area 10) (Haematoxylin and eosin $\times 375$ )

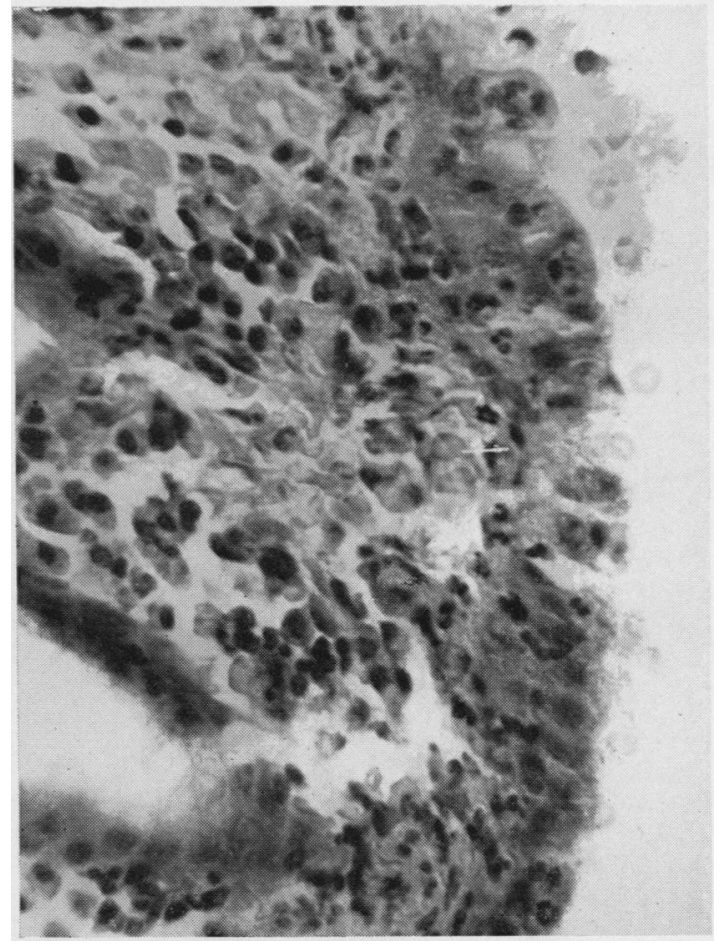

FIG. 5. Section showing abnormal surface epithelium in an area of active gastritis at the edge of a benign peptic ulcer. Same area as Fig. 4.

(Case G 97 area 6) (Haematoxylin and eosin $\times 310$ )

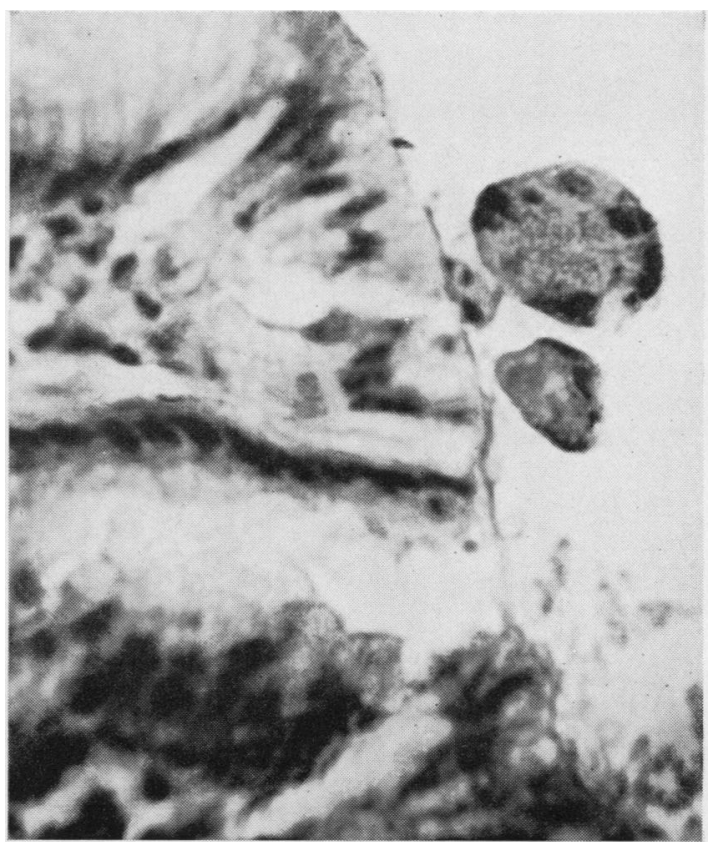

FIG. 7 

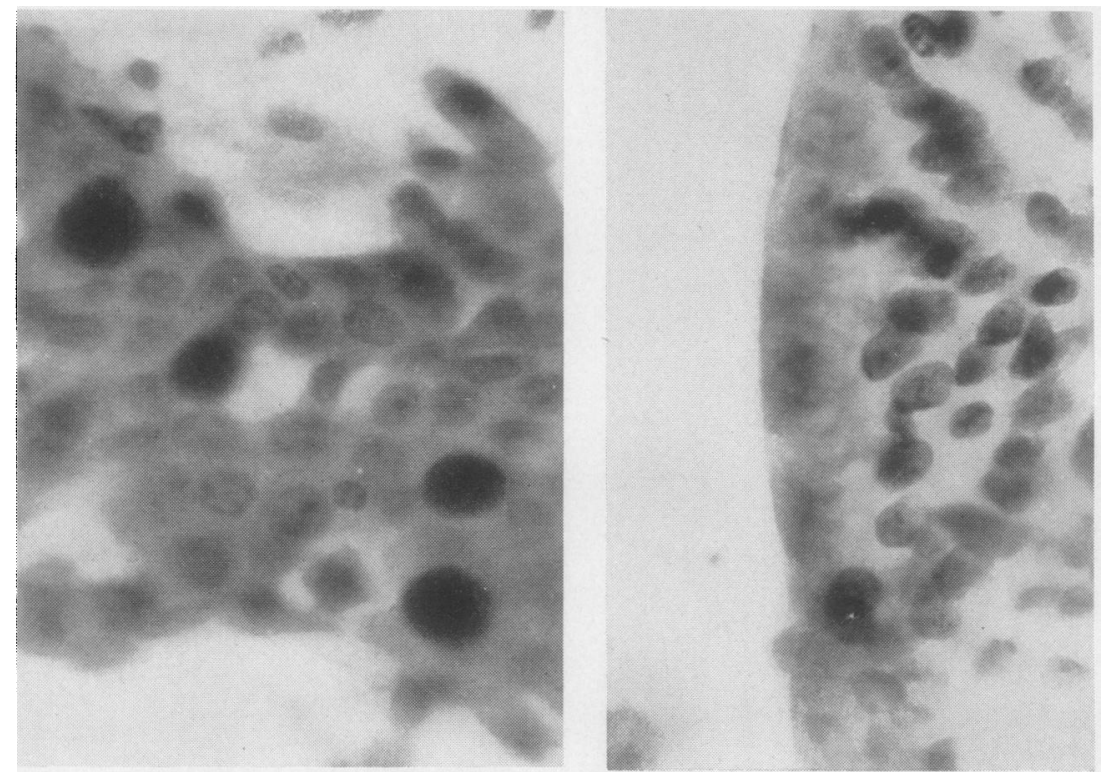

FIG. 8. Smears from areas of intestinal metaplasia of the stomach. Left, P.A.S. preparation showing 'goblets', similar to those in Fig. 3. (Case G 116 area 3) $(\times 700)$ Right, fragment showing cuticular border. (Case 38 area 5) (Mucicarmine $\times 700$ )

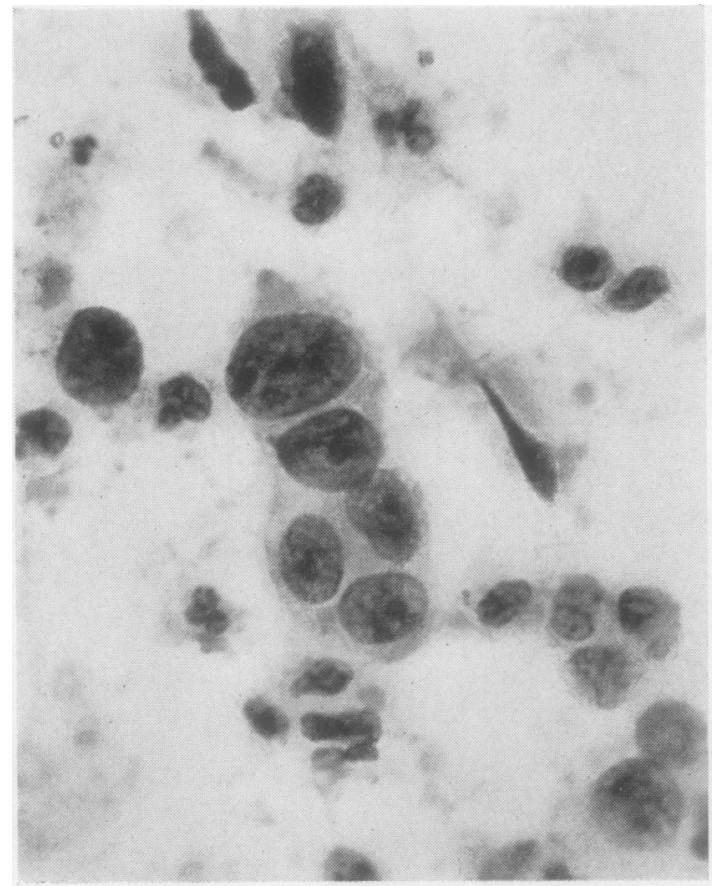

FIG. 9. Smear from gastric carinoma. These nuclei show the characteristic enlargement, hyperchromasia, variation in size, and prominence of nucleoli, exceeding the changes found in gastritis. (Case $G 117$ area 2) (Papanicolaou $\times 700$ )
INTESTINAL METAPLASIA Areas of intestinal metā plasia were found in one or more sections fron 16 cases. A carcinoma of the stomach was presenf in seven cases, a duodenal ulcer was present in si $\overrightarrow{\bar{B}}$ cases, and a gastric ulcer was present in three cases? In four cases of carcinoma large areas of mucos $\overrightarrow{\alpha_{4}}$ had undergone metaplasia, but in the others the. change was slight and focal. Goblet cells, a striateळ epithelial border, and Paneth cells were present i⿱ the metaplastic epithelium.

Intestinal metaplasia was also recognizable in the smears. The refractile 'honeycomb' of vacuoles was reduced or absent ${ }^{1}$, but the goblet cells were presen $\phi$ and were particularly prominent in smears staine $\bar{q}$ with mucicarmine or P.A.S. (Fig. 8). In some frage ments the cuticular or brush borders were weff shown (Fig. 8). The nuclei showed no characteristiø features.

GASTRIC CARCINOMA The cases included a diffuse anaplastic carcinoma (linitis plastica), a signet ring cell (mucus-secreting) adenocarcinoma, five cases of adenocarcinoma which showed varying degrees of glandular differentiation; also an early, poorly differentiated adenocarcinoma which was confine $\bar{\phi}$ to the mucosa at the edge of a benign peptig ulcer.

1Probably owing to gastritis: in gastric washings from cases of pernto cious anaemia, pieces showing intestinal metaplasia may have weII preserved refractile vacuoles. 


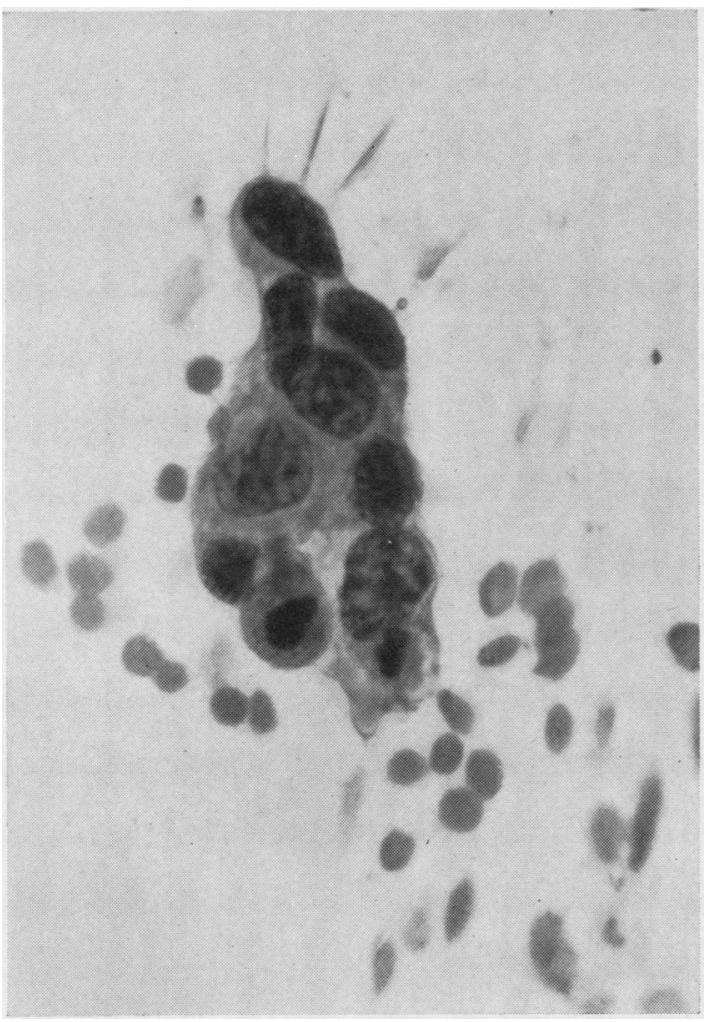

FIG. 10

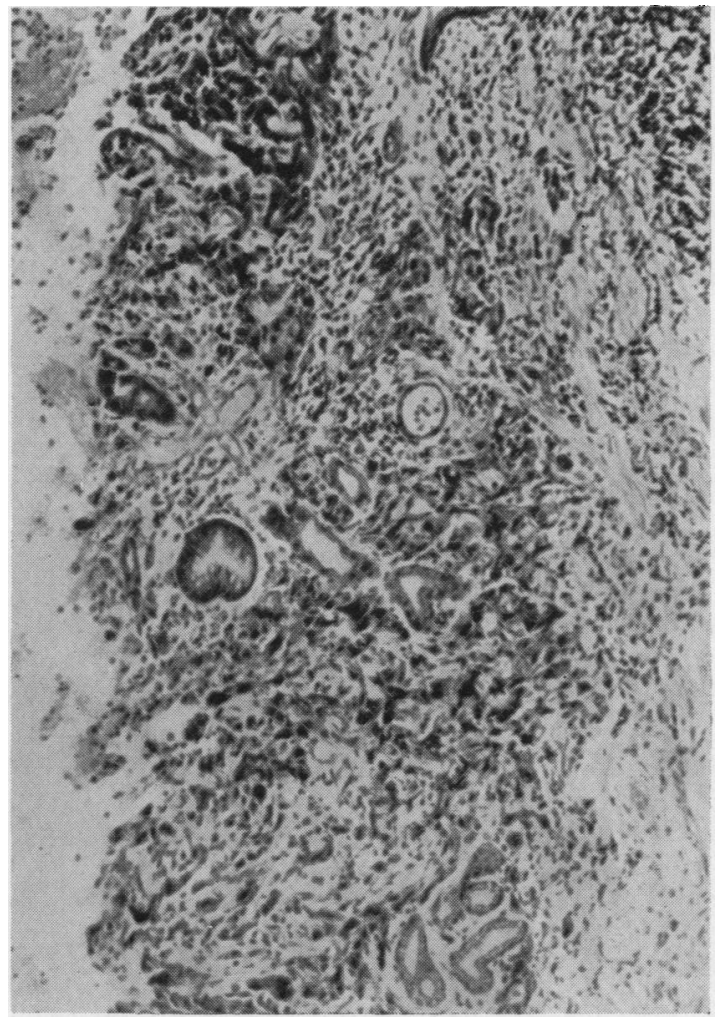

FIG. 11

FIG. 10. Smear from an unsuspected microscopical carcinoma at the edge of a peptic ulcer. (Case G 22 area 3) Papanicolaou $\times 700$ )

FIG. 11. Section of small, unsuspected, poorly differentiated gastric adenocarcinoma found at the edge of a peptic ulcer. The growth was confined to the mucosa. Same area as Fig. 10. (Case G 22 area 3) (Haematoxylin and $\operatorname{eosin} \times 140$ )

The tumour cells found in gastric scrapings in this series have fallen into three main groups, which correspond to the categories of cells found in gastric washings. First (Fig. 9) were cells occurring either separately or in small collections, with marked variation in size and shape of the nuclei, a high ratio of nucleus to cytoplasm, hyperchromasia, and enlargement of nucleoli. Such cells were not difficult to identify and nothing similar was found in chronic gastritis. If coherent pieces of tumour were scraped off as well, they had ill-defined edges and a very irregular and overcrowded appearance. The tendency of individual cells to come loose from the main mass was most characteristic and was not observed in benign conditions.

In one case of gastric ulcer which appeared benign to the naked eye, the scrapings showed cells of this type and the sections revealed a small early carcinoma at the edge of the ulcer (Figs. 10 and 11).
The second variety of tumour cell shown in the series was the signet ring cell. This was present in the scrapings in only one case (Fig. 12). Except for a considerable variation in size these cells showed no obvious malignant characteristics. The cells measured 15-35 $\mu$ across, and were mainly occupied by a foamy cytoplasm staining positively with P.A.S. and mucicarmine. The nuclei (generally one per cell, but sometimes two or three) lay eccentrically, measured 8-10 $\mu$ across, and showed distortions and foldings like those of macrophages. Very few of them were hyperchromatic. Unlike macrophages, they showed well-defined nucleoli.

The third type of tumour cells (encountered in three cases) seemed to show greater mutual adhesiveness, so that they came off in sheets. In one case, where loose malignant cells were also found, the large size of the nuclei made the diagnosis easy. Some nuclei measured as much as $20 \mu$ in one dia- 


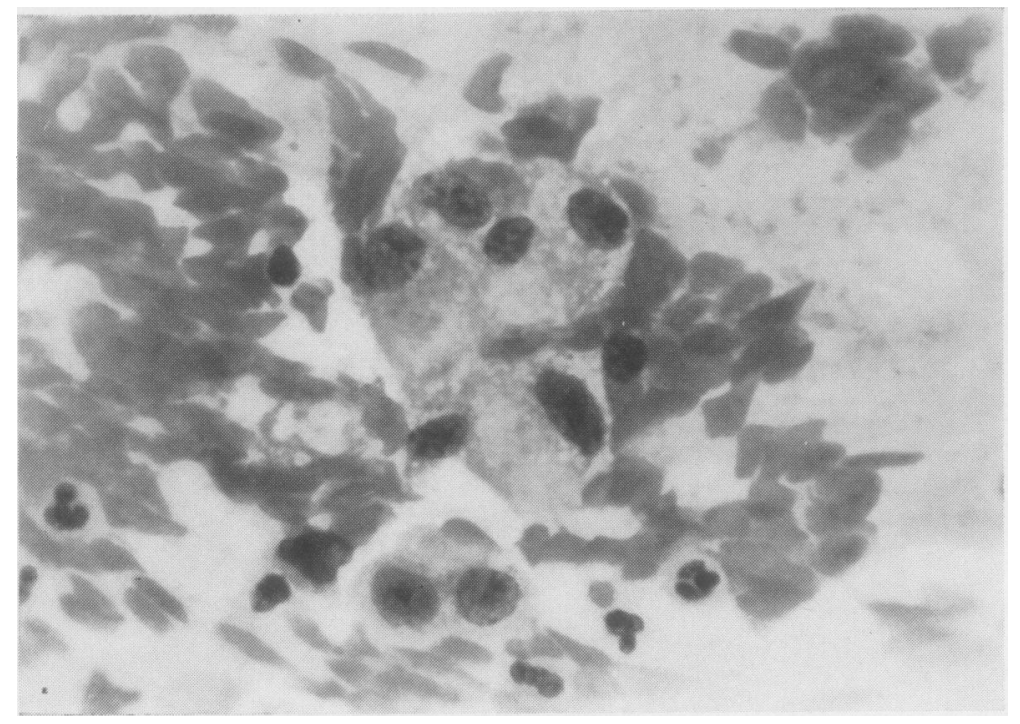

FIG. 12. Smear from a signet-ring carcinoma. The tumour cells have $\vec{\circ}$ foamy cytoplasm and eccentric nuclei larger than those of macro- $\vec{\omega}$ phages. (Case G 33 area 1) (Papanicolaou $\times 700$ )

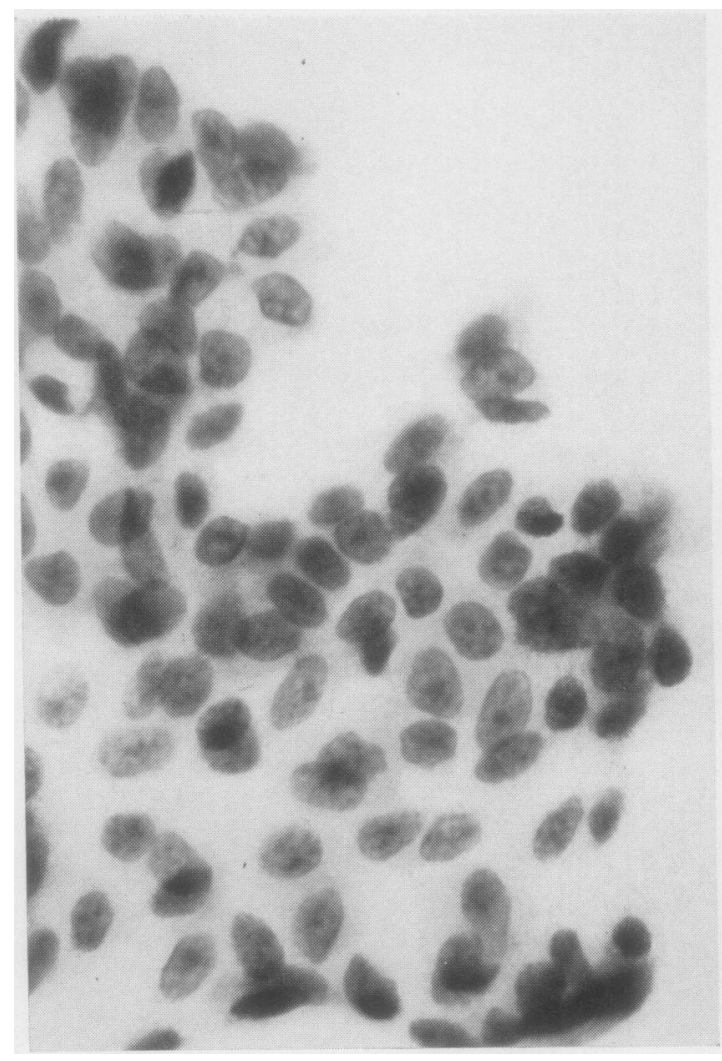

FIG. 13. Smear from a gastric carcinoma. In this case the cells came off in sheets with no sign of polarity, but the cells showed no greater cytological abnormalities than are sometimes found in chronic gastritis.

(Case G 116 area 1) $\quad($ Papanicolaou $\times 700)$

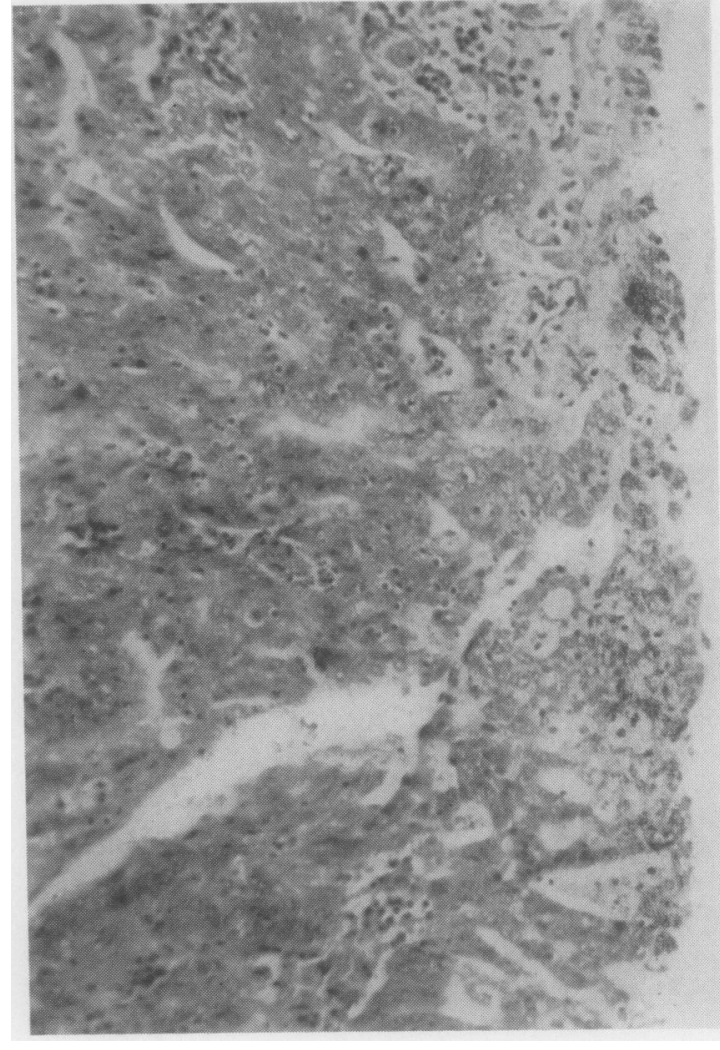

FIG. 14. Section showing the surface of a poorly dif. ferentiated adenocarcinoma of stomach. Same area a $\frac{\mathbb{0}}{\mathcal{O}}$ Fig. 13.

(Case G 116 area 1) (Haematoxylin and eosin $\times 140)$ 우 
meter. In another case, only an occasional nucleus $17 \mu$ long was outside the usual range for benign cells in gastritis. In the third case, the cells scraped from the tumour surface were, in our opinion, not individually distinguishable as malignant. Moreover, the degree of architectural disorder was not greater than was sometimes found in active gastritis; their main peculiarity was a tendency to separate as spindle cells. Small groups of these cells occurring in gastric washings would certainly be passed without suspicion (Figs. 13 and 14).

In one case of linitis plastica none of the smears showed any recognizable malignant cells. As far as could be seen from the corresponding sections, the tumour cells did not reach the surface of the mucosa.

\section{DISCUSSION AND CONCLUSION}

The morphological appearances of the cells obtained by scraping the mucous membrane of the excised stomach correspond closely with those of cells found in gastric washings. The results of this study seem therefore to be directly relevant to gastric "cytodiagnosis'. If enough cells of gastric origin can be found, it is possible to distinguish the following conditions:

NORMAL This is recognized by the regular architecture of the fragments, the 'honeycomb' of the mucus-secreting layer, and the absence of cellular infiltration. (This appearance has also been observed in gastric washings from cases of Addisonian pernicious anaemia.)

CHRONIC GASTRITIS The 'honeycomb' appearance is lost, the nuclei become variable, more darkly staining, and sometimes enlarged, and there is leucocytic infiltration. At times the appearances are indistinguishable from well-differentiated carcinoma.

INTESTINAL METAPLASIA This can be diagnosed from the finding of goblet cells and of cuticular or brush borders. Large fragments may show the actual architecture of villi. In gastric washings this finding indicates atrophic gastritis or gastric atrophy, and has been observed in pernicious anaemia.

CARCINOMA In most cases malignant cells are easily recognized by their large, irregular hyperchromatic nuclei with prominent nucleoli, their tendency either to separate from one another or to form crowded aggregates showing anisonucleosis, and sometimes by numerous mitoses. The signet ring type is also readily recognizable. However, no two malignant tumours are exactly alike, and the variations include forms in which the cells are not distinctive. In this very small series there are two examples in which the isolated cells could not be distinguished with certainty from types of cells found in the neighbourhood of a benign peptic ulcer.

This study therefore emphasizes the fact that in trying to diagnose carcinoma of the stomach from cytological evidence, we are working very near to the margin of what is humanly possible. Rubin and Benditt (1955), Raskin et al. (1958), and Schade (1960) have claimed that carcinoma can be diagnosed in this way in over $90 \%$ of cases, and consider that a negative finding is of actual diagnostic value in helping to exclude malignancy. Most other workers have had a higher proportion of 'false negative' findings. The present series illustrates two simple causes of failure: first, the malignant cells may not reach the lumen, and second, they may not be sufficiently distinctive morphologically for a definite diagnosis. False positive reports can only be avoided if the examiner is familiar with the aberrations which may occur in active gastritis, and direct comparisons such as ours are valuable in obtaining experience of these changes.

We are grateful to Dr. A. H. T. Robb-Smith for his advice and for reading the manuscript; also to our surgical colleagues who have kindly supplied us with material, and to Mrs. D. Jackson for photographs of the histological sections.

\section{REFERENCES}

Heinkel, K., Witte, S., Landgraf. S., and Elster, K. (1956). Ärztl. Wschr., 11, 597.

Henning, N., and Witte, S. (1957). Atlas of Gastroenterological Cytodiagnosis. Thieme, Stuttgart.

Joske, R. A., Finckh, E. S., and Wood, I. J. (1955). Quart. J. Med., 24, 269.

Magnus, H. A. (1946). J. Path. Bact., 58, 431.

Marini, G. (1909). Arch. Verdau.-Kr., 15, 251.

Palmer, E. D. (1954). Medicine (Baltimore), 33, 199.

Raskin, H. F., Kirsner, J. B., and Palmer, W. L. (1958). In Modern Trends in Gastro-enterology (Second Series), ed. F. Avery Jones, pp. 76-91. Butterworths, London.

Rubin, C. E. (1956). Ann. N.Y. Acad. Sci., 63, 1377. and Benditt, E. P. (1955). Cancer, 8, 1137.

Schade, R. O. K. (1958). Brit. med. J., 1, 743.

(1960). Gastric Cytology. Arnold, London. 